\title{
Y Kuşağı Gençlerin Huzurevinde Kalmayı Tercih Etme Eğilimleri: Nevşehir Örneği
}

\author{
DOI: $10.26466 /$ opus.622196
}

\author{
*

\section{Hamza Kurtkapan*} \\ * Dr. Öğr. Üyesi, Nevşehir Hacı Bektaş Veli Üniversitesi, Sağlık Hiz. MYO/ Nevşehir/Türkiye \\ E-Posta: hamzakurtkapan@nevsehir.edu.tr ORCID: 0000-0001-9815-7337
}

Öz

Bu çalışmada $Y$ kuşă̆g gençlerin yaşlılıklarında huzurevinde kalmayı tercih etme eğilimlerini incelenmektedir; bu amaçla gençlerin huzurevinde kalma ya da kalmama yönündeki isteklerinin başlıca gerekçelerine ve bu eğilimleri ile yaşam memnuniyeti arasındaki ilişkiye odaklanılmıştır. Ayrıca bu çalışmada cinsiyet, gelir ve mezun olunan lise türü gibi değişkenlerin yaşam memnuniyetine etkisini belirlemek hedeflenmektedir. Nicel araştırma deseni ile betimleyici bir kesitsel araştırma yürütülmüştür. Araştırma, Şubat ve Mart 2019 tarihleri arasında Nevşehir Hacı Bektaş Veli Üniversitesinde lisans eğitimine kayıtlı 18-27 yaş grubunda 775 katılımo ile yapılmıştır. Araştırma sonucunda yaşam memnuniyet puan ortalaması yüksek olan katılımcılarda ihtiyaç halinde huzurevini tercih etme eğiliminin daha az olduğu tespit edilmiştir. Araştırmada gençlerin yaşam memnuniyeti ölçeği puanlarının cinsiyete göre anlamlı farklılık göstermediği saptanmıştır. Ailesinin aylık ortalama gelirini 3250 TL ve üzeri olduğunu söyleyenlerin, 1700 TL ve aşă̆ısı olduğunu söyleyenlere oranla daha yüksek yaşam doyumuna sahip oldukları tespit edilmiştir. Ayrıca İmam Hatip Lisesi mezunu gençlerin Düz Lise mezunu gençlerden daha yüksek yaşam memnuniyetine sahip oldukları saptanmıştır. Elde edilen bulgular literatür ekseninde tartışılmıştır.

Anahtar Kelimeler: Gençlik Sosyolojisi, Huzurevi, Yaşam Memnuniyeti, Meslek Lisesi. 


\title{
The Tendency of the Youth to Prefer to Stay in a Nursing Home: The Case of Nevşehir
}

\begin{abstract}
In this study, it is aimed to examine the tendency of generation $Y$ to prefer to stay in a nursing home when they get older. It focuses on the main reasons why young people want to stay in nursing homes, and the relationship between these tendencies and life satisfaction. In addition, it is aimed to determine the effect of demographic variables such as gender, income and high school group on life satisfaction of them. A descriptive cross-sectional study was conducted with quantitative research design. The research was conducted between February and March 2019 with 775 people in the 18-27 age group enrolled in undergraduate education at Nevşehir Hacı Bektaş Veli University. As a result of the study, it was found that the tendency to prefer a nursing home is less among the participants with high average life satisfaction score. In the study, it was found that the scores of life satisfaction scale of the youth did not show statistically significant difference according to gender. Participants who belong to a family with the average monthly income of $3250 \mathrm{TL}$ and above have a higher life satisfaction than the participants with an average monthly income of $1700 \mathrm{TL}$ and low. In addition, it was found that participants who graduated from Imam Hatip High School have higher life satisfaction than those who graduated from other High Schools. The findings were discussed within the regard of the related literature.
\end{abstract}

Keywords: Sociology of Youth, Nursing Home, Life Satisfaction, Vocational High School 


\section{Giriş}

21. yüzyılda dünyada yaşanan iki önemli trendden birisi nüfus içerisinde yaşlıların oranının artmasıdır (WHO, 2007, s.1). Türkiye'de bu demografik dönüşüme bağlı olarak, toplam nüfus içerisinde 65 yaş ve üzeri bireylerin oranı hızla artmaktadır. Türkiye'de 2018 yılında $\% 8,7$ olan 65 yaş ve üzeri nüfusun 2040 yılında \%16'yı, 2060 yılında ise \%22'yi geçeceği ön görülmektedir (TÜİ, 2018). Aynı zamanda 2018 yılında \%22,6 olan 0-14 yaş grubu çocukların oranının 2060 yılında \%17'nin altına düşeceği de tahmin edilmektedir. Nüfus projeksiyonları 2050'li yılların sonlarına doğru 65 yaş üzeri nüfusun ilk defa 0-14 yaş arası çocuk nüfusundan daha fazla olacağını göstermektedir (TÜIKK, 2018).

Bayhan'a göre Türkiye şartlarında 1990 ve 2000 yılları arasında doğan günümüz gençleri Y kuşağını oluşturmaktadır (2014, s.4). Türkiye'de demografik anlamda kritik bir dönem olan 21. yüzyılın ikinci yarısında $Y$ kuşağındakiler yaşlılığa ilk adımlarını atacaktır. Dolayısıyla geleceğin $Y$ kuşağı yaşhları, kendilerinden önceki kuşaktakilerden daha fazla akademik ilgiyi hak etmektedir (Kurtkapan, 2019, s.4). Kritik bir tarihsel dönemde yaşlılığa adım atacak olan günümüz gençleri ile ilgili daha fazla çalışma yapmaya ihtiyaç vardır.

Yaş Tabakalaşması Kuramına göre, yaşlıların özellikleri dönemden döneme farklılık göstermektedir (Riley, 1976, s.30). Küreselleşmenin sık sık dile geldiği bir dönemde doğan ve tüketim kültürü ile büyüyen Y kuşağını, onlara özgü bir yaşlılık dönemi beklemektedir. Ayrıca bu kuşağın doğduğu 1980 sonrası yılların, neo-liberal politikaların egemen olduğu ve sosyal devletin küçüldüğü bir dönem olduğunu belirtmek gerekir (Kökalan-Çımrın, 2009, s.199). Bu dönemsel düşünüş biçimi, o dönemde doğup büyüyen $Y$ kuşağ1 bireylerin yaşlılık, yaşlı bakımı ve huzurevi gibi konulara bakış açlarında da etkili olmaktadır.

Türkiye'de nüfusun yaşlanmasının ekonomik, sosyal ve politik yansımaları vardır. Bu durum özellikle yaşlı bakımı rejimini etkilemektedir. Literatüre bakıldığında bireylerin huzurevi gibi kurumsal bakımı tercihleri modernleşme ve kentleşme düzleminde değerlendirilmektedir (Kurtkapan, 2018; Tufan, 2003; Kalınkara, 2000). Bu tercihlerde daha çok kuşaklararası ilişkilere odaklanılmaktadır (Kalaycıoğlu ve Rittersberger-Tılıç, 2001; Tufan ve Yazıcı, 2009; Alperen, 2013). Kuşaklararası ilişkiyi ele alan çalışmalarda genel amaç yaşlı bakımında devlet, piyasa ve aile üçgeninde sorumluluğun nasıl 
paylaşıldığını anlamaya çalışmaktır (Özbay, 2014, s.56). Genel olarak literatürde ailenin yaşlı bakımında önceliğe sahip olması gerektiği vurgulanmaktadir.

Türkiye'de geleneklerin de etkisi ile ihtiyaç halinde yaşlı bakımının evde yapılması hem yaşlının kendisinin hem de yaşlı yakınının tercihi olmaktadır (Görgün-Baran, 2005; Aközer, vd. 2011). Ailenin yetersiz kaldı̆̆ı durumlarda ise devlet, huzurevi gibi kurumları devreye sokmaktadır. Türkiye şartlarında huzurevinde 60 yaş ve üzeri sağlıklı bireylere yatılı hizmet verilmektedir (Özmete ve Hussein, 2017 s.7). Ancak yaşlı bireylere yönelik huzurevi hizmetinin maliyeti yüksek olduğundan kamu tarafından pek fazla tercih edilmemektedir (Bilge, vd. 2014). Yine de bazı bireyler çeşitli nedenlerden dolayı huzurevini tercih edebilmektedir. Bu nedenlerin başında modern dönemde ailede yaşanan yapısal değişim gelmektedir. Ailedeki değişimin temelinde kentleşme, nüfus artışı, üretim biçimindeki değişimler ve iş piyasasındaki dönüşüm yer almaktadır. Bu değişimler, yaşlı bakımı konusunu etkilemekte ve bireylerin huzurevi gibi kurumlara olan ihtiyaçlarını artırmaktadır.

Bireylerin huzurevi tercihlerinde sosyal faktörlerin etkisi kadar, kişinin öznel durumu da etkili olmaktadır. Örneğin bireylerin yaşam memnuniyetleri, onların tercihlerini belirlemektedir (Cirhinlioğlu ve Ok, 2010, s.3). Yaşam memnuniyeti, çeşitli kriterler ekseninde bireyin kendi yaşam ve deneyimlerine ilişkin yaptığı anlık genel değerlendirmedir (Diener, Emmons, Larsen, Griffin, 1985, s.71). Bireylerin yaşam memnuniyeti aynı zamanda onların huzurevinde kalmaya ilişkin eğilimlerini de etkilemektedir.

Bu araştırmada Nevşehir Hacı Bektaş Veli Üniversitesi 2018-2019 güz dönemine kayıtlı lisans öğrencilerinden oluşan $Y$ kuşağına mensup bir grup gencin yaşlılıklarında huzurevinde kalmayı tercih etme eğilimleri değerlendirilmiştir. Gençlerin huzurevinde kalma ya da kalmama yönündeki tercihlerinin başlıca gerekçelerine bakılmıştır. Huzurevi tercih eğilimleri ile yaşam memnuniyeti arasındaki ilişki analiz edilmiştir. Ayrıca bu çalışmada cinsiyet, gelir ve mezun olunan lise grubu gibi demografik değişkenlerin yaşam memnuniyetine etkilerinin belirlenmesi hedeflenmiştir. Araştırmanın genel amacına uygun olarak aşağıda belirtilen alt problemlere cevap aranmıştır:

- Y kuşağı genç katılımcıların yaşam memnuniyet puanları ile huzurevinde kalmayı tercih etme eğilimleri arasında anlamlı bir ilişki var midir? 
- Y kuşağı genç katılımcıların yaşam memnuniyet puanları cinsiyet değişkenine göre anlamlı bir farklılık göstermekte midir?

- Y kuşağı genç katılımcıların yaşam memnuniyet puanları gelir değişkenine göre anlamlı bir farklılık göstermekte midir?

- Y kuşağı genç katılımcıların yaşam memnuniyet puanları mezun olunan lise değişkenine göre anlamlı bir farklılık göstermekte midir?

\section{Yöntem}

\section{Araştırmanın Türü ve Örneklemi}

Araştırmada nicel araştırma yöntemi ile betimleyici ve kesitsel tipte bir çalışma yapılmıştır. Y kuşağına mensup bir grup gencin yaşlılıklarında huzurevinde kalmayı tercih etme eğilimleri incelenmiştir. Araştırma, Şubat- Mart 2019 tarihleri arasında yapılmıştır. Bu araştırmanın evrenini Nevşehir Hacı Bektaş Veli Üniversitesinde Lisans eğitimi gören 18-27 yaş aralığındaki gençler oluşturmuştur. Araştırmanın örneklem grubunu oluşturan 775 katılımcıya basit rastlantısal örneklem yöntemi ile ulaşılmıştır. Katılımcılara ait demografik bilgiler, Tablo-1'de gösterilmektedir.

Tablo 1. Katılımciların demografik özellikleri.

\begin{tabular}{lll}
\hline Cinsiyet & f & $\%$ \\
\hline Kadın & 535 & 69 \\
Erkek & 240 & 31 \\
\hline Doğduğu, büyüdüğ̈̈ yer & & \\
\hline Kır/köy & 260 & 33,5 \\
Kent & 504 & 65,1 \\
Cevap yok & 11 & 1,4 \\
\hline Ailenin aylık ortalama geliri & & \\
\hline 0-1700 TL & 165 & 21,3 \\
1701- 2100TL & 151 & 19,5 \\
2101-3250 TL & 168 & 21,7 \\
3251 TL ve üzeri & 160 & 20,6 \\
Cevap yok & 131 & 16,9 \\
\hline Aile Tipi & & \\
\hline Çekirdek Aile & 675 & 87,1 \\
Genis Aile & 87 & 11,2 \\
Cevap yok & 13 & 1,7 \\
\hline Toplam & 775 & 100 \\
\hline
\end{tabular}


Tablo 1'de görüleceği üzere, katılımcıların 535'i (\%69) kadın; 240'1 (\%31) erkeklerden oluşmaktadır. Katılımcların 504'ü (\%65,1) kent, 260'1 $(\% 33,5)$ ise kır/köy doğumludur. Katılımcların 165 'i $(\% 21,3)$ ailelerinin ortalama aylık gelirinin 1700 TL'den aşağı olduğunu belirtmiştir. Katılımc1ların 675'i $(\% 87,1)$ çekirdek ailede, 87 'si $(\% 11,4)$ ise geniş ailede doğup büyüdüklerini ifade etmiştir. Kesitsel tipteki bu araştırmanın sonuçları sadece uygulandığı bu gruba genellenebilir.

\section{Veri Toplama Aracı}

Araştırmada veriler, anket formu aracılığı elde edilmiştir. Anket formu iki bölümden oluşmaktadır. Birinci bölümde, katılımcıları tanıtıcı bilgi soruları yer almaktadır. İkinci kısımda ise yaşam memnuniyeti ölçeği bulunmaktadır. Tanıtıcı bilgi soruları, araştırmaya katılan gençlerin sosyal ve demografik özelliklerini (yaş, cinsiyet, aylık ortalama gelir, mezun olunan lise) belirlemeyi amaçlamaktadır. İlk bölümde ayrıca katılımcıların ihtiyaç duyduklarında huzurevinde kalmayı düşünüp düşünmedikleri de sorulmuştur.

Yaşam Memnuniyeti Ölçeği: Yaşam Memnuniyeti Ölçeği, Diener ve arkadaşları tarafından 1985 yılında geliştirilmiştir. Ölçek, 5 maddeden oluşmakta olup tek boyutludur. Ölçekte kişinin kendi yaşamının niteliği hakkındaki genel değerlendirmelerini ortaya çıkarmak amaçlanmaktadır. Yaşam Doyum Ölçeğini Türkçeye uyarlayan Dağlı ve Baysal (2016) ölçeğin bütünü için Cronbach Alpha tutarlılık katsayısının 0,88 olduğunu tespit etmiştir. Bu araştırmada ölçeğin Cronbach Alpha katsayısı 0,83 olarak hesaplanmıştır. Bu ölçek, bireyin kendi yaşam kalitesine ve iyilik haline ilişkin algısını ölçmeye çalışmaktadır. Ayrıca yaşam memnuniyeti ölçeği bireyin kendi yaşamına yönelik genel değerlendirmesini içermektedir.

\section{Anket Formunun Uygulanması.}

Araştırma öncesi Nevşehir Hacı Bektaş Veli Üniversitesinden 16.01.2019/1 karar tarihli Etik Kurul onayı alınmıştır. Yanı sıra ilgili Fakülte yönetimlerinden ve katılımcılardan gerekli izinler alınmıştır. Anketin işlerliğini 
test etmek üzere 20 katılımcı ile pilot uygulama yapılmıştır. Pilot uygulama sonrası, ankette gerekli düzeltmeler yapıldıktan sonra, anket uygulaması Şubat ve Mart 2019 tarihlerinde öğrenciler ile sınıf ortamında yapılmıştır. Verilerin analizinde SPSS 25.0 programından yararlanılmıştır. Verilerin değerlendirilmesinde tanımlayıcı istatistik metotlar kullanılmıştır. İstatistiksel veriler değerlendirilirken bağımsız gruplar t-Testine başvurulmuştur. Bulgular \%95 güven aralığında değerlendirilmiştir. Yarı yapılandırılmış açık uçlu sorular değerlendirilirken kategorik içerik analizine tabi tutulmuştur.

\section{Bulgular}

Bu bölümde 18-27 yaş aralığındaki katılımcılara uygulanan anketten elde edilen verilerden hareketle yapılan analizlere yer verilmektedir. Bu bölümde araştırmanın amacına ulaşmak için iki adet analiz yapılmıştır. İlk olarak gençlerin huzurevi tercihlerini etkileyen faktörlere bakılmıştır. Bu çerçevede öncelikle katılımcıların ihtiyaç halinde huzurevinde kalma eğilimlerinin frekansına bakılmıştır. Daha sonra huzurevi tercihine dair evet ve hayır cevaplarının nedenlerine ilişkin açık uçlu sorulara verilen cevaplar analize dahil edilmiştir. Ayrıca gençlerin huzurevinde kalma eğilimleri ile yaşam memnuniyetleri arasındaki ilişki analiz edilmiştir. İkinci analizde ise katılımcıların Yaşam Memnuniyeti Ölçeğinden aldıkları puanların cinsiyet, aylık ortalama gelir ve mezun olunan lise türüne göre değişiklik gösterip göstermediğine bakılmıştır.

\section{Y Kuşağı Gençlerin Huzurevinde Kalmayı Tercih Etme Ĕ̆ilimleri}

90’lı yıllarda doğan Y kuşağına mensup gençler 2055 ve sonrası yıllarda yaşlılığa ilk adımı atacaktır. Nüfus içerisinde yaşlıların oranının çocukların oranını ilk defa geçeceği tarihî bir dönemde yaşlılı̆̆a adım atacak olan bu gençlerin, yaşlılık dönemine ilişkin görüşleri ve huzurevinde kalıp kalmama yönündeki tercihleri önem kazanmaktadır. 
Tablo 2. Katılımcıların ihtiyaç duyacak kadar yaşlanınca huzurevinde kalmak isteyip istememe eğilimleri

\begin{tabular}{lll}
\hline İhtiyaç duyacak kadar yaşlanınca huzurevinde kalmayı ister misiniz? & $\mathbf{f}$ & $\mathbf{\%}$ \\
\hline Evet & 161 & 20,8 \\
Hayır & 640 & 78,7 \\
Cevap yok & 4 & 0,5 \\
\hline Toplam & 775 & 100 \\
\hline
\end{tabular}

Tablo 2'de görüleceği üzere araştırmaya katılanların 161'i (\%20,8) ihtiyaç duyacak kadar yaşlandığı zaman huzurevinde kalabileceklerini ifade etmiştir. Katılımcıların 640'1 $(\% 78,7)$ ise bu soruya hayır cevabını vermiştir.

Y Kuşă̆ı Gençlerin Huzurevinde Kalmaya Yönelmelerini Etkileyen Faktörler

Katılımcıların ihtiyaç duyacak kadar yaşlanınca huzurevinde kalmaya evet ya da hayır cevabının nedenleri açık uçlu olarak sorulmuştur. Bu soruya verilen cevaplar kategorik analize tabi tutulmuştur. Analiz sonuçları Tablo 3 ve Tablo 4'te verilmiştir.

Tablo 3. İhtiyaç duyacak kadar yaşlanınca huzurevinde kalma tercihinin nedeni

\begin{tabular}{lll}
\hline Neden huzurevinde kalabileceğini düşünüyorsun? & $\mathrm{f}$ & $\%$ \\
\hline Kimseye yük olmak istemediğim için, & 30 & 39,48 \\
Ailede kimsenin bakmak istemeyeceği için, & 15 & 19,73 \\
Daha iyi bakım için, & 19 & 25,00 \\
Akranlarım ile birlikte olabilmek için, & 12 & 15,79 \\
\hline Bu soruyu cevaplayanları toplamı & 76 & 100 \\
\hline
\end{tabular}

Tablo 3'de görüleceği üzere katılımcılar en fazla yaşlılık döneminde kimseye yük olmak istemediği için huzurevini tercih etmektedir (Cevap verenlerin $\left.\% 39,48^{\prime} i\right)$. Bu soruyu cevaplayan katılımcıların 15'i $(\% 19,73)$ ailede kimsenin bakmak istemeyeceğini ifade etmiştir. Diğer taraftan huzurevinin olumlu yanına vurgu yaparak burada kalabilirim cevabını verenlerin oranı bu soruya cevap verenlerin \%40'1nı geçmektedir. Bunlardan $19^{\prime}$ u $\left(\% 25^{\prime}\right)$ yaşlanınca huzurevinde daha iyi bakım alabileceğini düşün- 
mektedir. Bu soruyu cevaplayanların 12'si $(\% 15,79)$ ise huzurevinin akranları ile birlikte olabilmeye imkân tanımasını evet cevabına gerekçe göstermiştir.

Tablo 4. Huzurevinde kalmama tercihinin nedenine dair açık uçlu soruya verilen cevapların kategorileştirilmesi.

\begin{tabular}{lll}
\hline Neden huzurevinde kalamayacağını düşünüyorsun? & $\mathrm{f}$ & $\%$ \\
\hline Aile yanında ve evimde yaşamak istediğim için, & 112 & 42,26 \\
$\begin{array}{l}\text { Huzurevinde bakımın iyi olmayacağı ve ailede daha iyi bakılacağı için, } \\
\text { Kendimi huzurevinde dışlanmış ve psikolojik olarak kötü hissedeceğim }\end{array}$ & 51 & 19,25 \\
$\begin{array}{l}\text { için, } \\
\begin{array}{l}\text { Huzurevi fikrinin bana sıcak gelmediği ve orada rahat edemeyeceğim } \\
\text { için, }\end{array}\end{array}$ & 21,89 \\
\hline Bu açık uçlu soruyu cevaplayanları toplamı & 16,60 \\
\hline
\end{tabular}

Tablo 4'de görüleceği üzere huzurevinde kalmama yönündeki tercihlerinin nedenini açıklayan 265 katılımcının 112'si $(\% 42,46)$ ailesinin yanında ve/veya evinde yaşamak istediği için huzurevi bakımını düşünmediğini belirtmektedir. Bu soruyu cevaplayan katılımcıların 58'inin $(\% 21,89)$ huzurevinde dışlanmışlık, yalnızlık hissi yaşayacakları ve psikolojik olarak kötü hissedecekleri için huzurevini düşünmedikleri tespit edilmiştir. Bu soruya cevap verenlerin 51'i $(\% 19,25)$ huzurevinde bakımın iyi olmayacağını ve bunun yerine ailede daha iyi bakım alabileceğini düşündüğü için huzurevinde kalmaya hayır cevabını vermiştir. Son olarak "Huzurevinde kalmak ister misin?" sorusuna hayır cevabının nedenini açıklayanların $44^{\prime} \ddot{u}(\% 16,60)$ huzurevi fikrinin onlara sıcak gelmediğini ve orada rahat edemeyeceklerini düşündüklerini belirtmiştir.

\section{Y Kuşağı Gençlerin Huzurevinde Kalma Ĕ̆ilimleri İle Yaşam Memnuni- yetleri Arasındaki İlişki}

Huzurevinde kalma tercihi çok çeşitli sosyal ve psikolojik faktörlerden etkilenmektedir. Araştırma çerçevesinde, yaşlılıkta muhtaç duruma gelindiği takdirde huzurevinde kalıp kalmama yönündeki tercihleri ile yaşam memnuniyeti arasındaki ilişki bağımsız gruplar t-testi ile analiz edilmiş ve analiz sonuçları Tablo 5'de verilmiştir. 
Tablo 5. Yaşam Memnuniyeti Ölçeğinden alınan puan ortalamalarının katılımcının huzurevinde kalma/kalmama tercihi değişkenine göre farklılaşıp farklılaşmadığını belirlemek üzere yapılan bağımsız gruplar t-Testi sonuçları

\begin{tabular}{llllllllll}
\hline Puan & $\begin{array}{l}\text { Huzurevinde } \\
\text { kalmayı } \\
\text { misin? }\end{array}$ & $\mathbf{N}$ & $\mathbf{X}$ & Ss & Shx & t-Testi & \\
\cline { 6 - 9 } & & & & & & $\mathbf{t}$ & Sd & P \\
\hline Yaşam & Evet & 161 & 14,68 & 4,33 & 0,34 & $-1,98$ & 769 & 0,047 \\
Memnuni- & Hayır & 610 & 15,44 & 4,35 & 0,17 & & & \\
yeti Ölçeği & & & & & & & & & \\
\hline
\end{tabular}

Tablo 5'de görüldüğü üzere katılımcıların huzurevinde kalma/kalmama tercihleri ile yaşam memnuniyeti puanlarının aritmetik ortalamaları arasındaki fark istatistiksel olarak anlamlı bulunmuştur $(\mathrm{t}=-1,98$; $\mathrm{p}=0,047 ; \mathrm{p}<0,05)$. Bu fark huzurevinde kalmaya hayır cevabını verenler lehinedir. Diğer bir ifade ile ihtiyaç halinde huzurevinde kalmayı düşünen katılımcıların, daha yüksek bir yaşam memnuniyeti ortalamasına sahip oldukları tespit edilmiştir.

Katılımcılarn Cinsiyet, Ailenin Ortalama Aylık Geliri ve Mezun Olunan Lise Değişkenlerine Göre Yaşam Memnuniyetleri

Gençlerin yaşam memnuniyetlerinin cinsiyet, aylık ortalama gelir ve mezun olunan lise değişkenlerine göre farklılaşıp farklılaşmadı̆̆ını ortaya koymak amacıyla bağımsız gruplar t-testi yapılmıştır. Analiz sonuçları aşağıda Tablo $6^{\prime}$ da verilmiştir.

Tablo 6. Yaşam Memnuniyeti Ölçeğinin katılımcının cinsiyet, aylık ortalama gelir ve mezun olunan lise değişkenlerine göre farklılaşıp farklılaşmadı̆̆ın belirlemek üzere yapılan bağımsız gruplar t-testi sonuçları

\begin{tabular}{|c|c|c|c|c|c|c|c|c|}
\hline \multirow{2}{*}{ Puan } & \multirow{2}{*}{ Değişkenler } & \multirow{2}{*}{$\mathbf{N}$} & \multirow{2}{*}{$x$} & \multirow{2}{*}{ Ss } & \multirow{2}{*}{ Shx } & \multicolumn{3}{|c|}{ t-Testi } \\
\hline & & & & & & $t$ & Sd & $\mathbf{P}$ \\
\hline \multirow{6}{*}{$\begin{array}{l}\text { Yaşam } \\
\text { Memnuni- } \\
\text { yeti Ölçeği }\end{array}$} & Kadın & 535 & 15,36 & 4,23 & 0,18 & 0.90 & 773 & 0.36 \\
\hline & Erkek & 240 & 15,05 & 4,68 & 0,30 & & & \\
\hline & $0-1700 \mathrm{TL}$ & 165 & 14,73 & 4,33 & 0,33 & $-3,10$ & 323 & $0,02^{*}$ \\
\hline & $\begin{array}{lll}3251 & \text { TL } & \text { ve } \\
\text { üzeri } & & \end{array}$ & 160 & 16,22 & 4,30 & 0,34 & & & \\
\hline & Düz Lise & 173 & 14,63 & 4,40 & 0,33 & $-3,24$ & 339 & $0,001^{*}$ \\
\hline & İ. Hatip Lise & 168 & 16,13 & 3,98 & 0,30 & & & \\
\hline
\end{tabular}


Tablo 6'da görüldügü üzere örneklemi oluşturan gençlerin yaşam memnuniyeti ölçeği puan ortalamalarının cinsiyet değişkenine göre anlamlı bir farklılık gösterip göstermediğini belirlemek amacıyla gerçekleştirilen bağımsız gruplar t-testi sonucunda, grupların aritmetik ortalamaları arasındaki fark istatistiksel olarak anlamlı bulunmamıştır $(\mathrm{t}=0,90$; $p=0,36 ; p>0,05)$. Diğer taraftan katılımcıların aylık ortalama gelirleri ile Yaşam Memnuniyeti Ölçeğinden aldıkları puan ortalamalarının arasındaki fark istatistiksel olarak anlamlı bulunmuştur ( $t=-3,10 ; p=0,02 ; p<0,05)$. Söz konusu farklılık aylık ortalama geliri yüksek olan katılımcıların lehine gelişmiştir. Benzer şekilde katılımcıların Yaşam Memnuniyeti Ölçeği puan ortalamalarının katılımcıların mezun olduğu lise türüne göre aritmetik ortalamaları arasındaki fark da istatistiksel olarak anlamlı bulunmuştur ( $\mathrm{t}=-$ 3,24; $\mathrm{p}=0,001 ; \mathrm{p}<0,005)$. Bu fark İmam Hatip Lisesi mezunları lehine tespit edilmiştir.

\section{Sonuç ve Tartışma}

Araştırmamıza katılan 90'lı yıllarda doğan Y kuşağına mensup gençler, 2050 yılı ve sonrası dönemde yaşlılığa adım atacaklardır. Türkiye' de nüfus içerisinde yaşlıların oranının 0-14 yaş grubu çocukların oranından ilk defa fazla olacağının ön görüldüğü bu dönemde yaşlılığa adım atacak olan bu gençlerin genel olarak kurumsal yaşlı bakımı ile ilgili görüşleri, özel olarak ise huzurevinde kalmayı isteyip-istememe konusundaki görüşleri önem kazanmaktadır. Araştırmaya katılanların büyük çoğunluğu ihtiyaç duyacak kadar yaşlanıldığında da huzurevinde kalmayı düşünmediğini belirtmektedir. Literatürde benzer sonuçlar yer almaktadır. Örneğin İstanbul'da lise öğrencileri ile yapılan bir araştırmada da benzer sonuca ulaşılmıştır. Yıldız'ın bu çalışmasında katılımcıların \%88,3'ü yaşlanınca huzurevinde kalmak istemediğini belirtmektedir (2018, s. 78). Benzer şekilde 2011 yılında yapılan Türkiye Aile Yapısı Araştırmasında 18-60 yaş aralığındaki bireylere kendilerine bakamayacak kadar yaşlandıklarında nasıl yaşamayı tercih ettikleri sorulduğunda, fikrim yok seçeneği d1şarıda bırakılırsa, cevap verenlerin ancak \%17'si yaşlandığında huzurevinde kalmayı düşündüğünü, \%83'ü ise huzurevinde kalmayı düşünmediğini ifade etmiştir. (Eryurt, 2014, s. 104). 
Araştırmada huzurevinde kalmak istememe nedenini açıklayan katılımcıların yarıya yakını ailesinin yanında ve/veya evinde yaşamak istediği için huzurevi bakımını düşünmediğini belirtmiştir. Beşte biri huzurevinde dışlanmışlık, yalnızlık hissi yaşayacağını belirtmiş ve psikolojik olarak kötü hissedeceği için huzurevini düşünmediğini söylemiştir. Diğer bir beşte birlik kesim ise huzurevinde bakımın iyi olmayacağ yerine ailede daha iyi bakım alabileceğini düşündüğü için huzurevinde kalmaya hayır cevabını vermektedir. Altıda birlik kesim ise huzurevi fikrine sıcak bakmadığı ve orada rahat edemeyeceği için hayır cevabını verdiğini belirtmiştir.

Diğer taraftan huzurevinde kalabileceğini söyleyen katılımcılar en yoğun olarak kimseye yük olmamak için huzurevini tercih edebileceklerini belirtmektedir (Cevap verenlerin yarıya yakını). Benzer şekilde yaklaşık beşte birlik kesim aileden kimsenin bakmak istemeyeceği için cevabını vermiştir. Diğer taraftan dörtte birlik kesim huzurevinde daha iyi bakılacağı için huzurevinde kalmayı istediğini belirtmektedir. Yaklaşık altıda birlik bir kesim ise akranları ile vakit geçirmek için huzurevinde kalmayı tercih edebileceğini belirtmiştir.

Türkiye İstatistik Kurumu tarafından 21011 yılında yapılan Türkiye Aile Yapısı Araştırması verilerine göre de Türkiye'de huzurevi tercih nedeni olarak \%50,2 ile çocuklarına yük olmak istememe seçeneği öne çıkmaktadır. Aynı araştırmada katılımcıların \%14,3'lük bir kesimi ise çocuklarım benimle yaşamak istemeyebilir seçeneğini işaretlemiştir (TAYA, 2011, s.365). 2016 yılını kapsayan Türkiye Aile Yapısı Araştırması sonuçlarına göre ise yaşlı bireylerin kendilerine bakamayacak kadar yaşlandıklarında huzurevinde kalmayı istemelerinin en önemli nedeni \%48,9 ile yine çocuklarına yük olmayı istememeleri olmuştur. İkinci en önemli neden ise \%20,2 ile huzurevlerindeki imkânların daha rahat olması, üçüncü en önemli neden ise \%11,2 ile çocuklarının kendileriyle birlikte yaşamayı istememeleri olmuştur (Karakuş, 2018, s.85).

Bu çalışmada katılımcıların orta düzeyde yaşam doyumuna sahip oldukları tespit edilmiştir. Literatürde diğer çalışmalarda benzer sonuçlara ulaşıldığı görülmektedir. Örneğin Toker ve Kalıpçı'nın araştırmasında da katılımcı çalışanların orta düzey bir yaşam memnuniyetine sahip olduğu 
tespit edilmiştir (2019, s. 555). Başka bir çalışmada ise katılımcıların ortalamanın üzerinde bir yaşam doyumuna sahip oldukları tespit edilmiştir (Balcı ve Koçak, 2017).

Literatürde ülkemizdeki gençlerin yaşam memnuniyetlerini inceleyen çalışmalar daha çok öğrenciler ile yürütülmüştür (Telef, Uzman ve Ergün, 2013). Bu çalışmalar gençlerin yaşam memnuniyetine etki eden faktörlere odaklanmıştır. Gençlerin yaşam memnuniyetleri ile onların huzurevini tercih etme eğilimleri arasındaki ilişkiye odaklanılmamıştır. Bu çalışmada bu ilişki analiz edilmiştir. İhtiyaç duyacak kadar yaşlanınca huzurevinde kalmayı düşünmüyorum cevabı veren katılımcların, huzurevine evet cevabı veren katılımcılara oranla daha yüksek bir yaşam memnuniyetine sahip oldukları tespit edilmiştir.

Kurumsal yapıların toplumsal düzenin işleyişi üzerindeki etkisini bireylerin tercihleri üzerinden okumakta fayda vardır. Her ne kadar huzurevi kurumsal bir yapıyı ifade etse de, bireylerin huzurevinde kalma tercihlerinin altında yatan öznel mekanizmaları okumak gerekmektedir. Bu çerçevede huzurevinde kalıp kalmama tercihi yaşam memnuniyetinin bir sonucu ise başka türlü bir toplum okuması yapmak gerekebilir. Eğer ki yaşam memnuniyet düzeyi yüksek olanlar huzurevini daha az tercih ediyorsa, bu durum toplum tarafından huzurevinde yaşama tercihinin bir tür normalden sapma olarak algılandığını gösterebilmektedir. Evde ve ailede geleneksel bakım, normatif düzlemde bireylerin yaşam kalitesi ve çevre ile olan ilişkileri arasında bir denge sağlanmasını gerektirmektedir. Bu çerçevede karşılaşılabilen olumsuzluklar ise farklılıklara odaklanma ihtiyacını doğurmaktadır. Ayrıca yaşam memnuniyeti pek çok şeye bağlı olarak değişebilen kompleks bir konudur.

Yapılan araştırmalar göstermektedir ki; bireylerin yaşam memnuniyetleri üzerinde cinsiyet, yaş, medeni durum, ekonomik faktörler gibi sosyal değişkenler de etkili olmaktadır (Diener, 1984; Mroczek ve Kolarz, 1998). $\mathrm{Bu}$ çalışmada katılımcı gençlerin yaşam memnuniyetinin cinsiyete göre değişmediği tespit edilmiştir. Literatürde benzer şekilde, yaşam doyumu ile cinsiyet arasında anlamlı bir ilişkinin olmadığını belirten çalışmalar yer almaktadır (Ergin, vd., 2011; Avşaroğlu, Deniz ve Kahraman, 2005). Diğer taraftan erkeklerde kadınlara oranla daha yüksek bir yaşam doyumu tespit eden araştırmalarda bulunmaktadır. (Balcı ve Koçak, 2017). Araştırmada, aylık ortalama gelirleri yüksek olan katılımcıların düşük olanlara 
oranla daha yüksek bir yaşam memnuniyetine sahip oldukları tespit edilmiştir. Son olarak İmam Hatip Lisesinden mezun olan katılımcıların, Düz Lise mezunu katılımcllara oranla daha yüksek bir yaşam memnuniyetine sahip oldukları tespit edilmiştir.

Geleceğin yaşlıları olan Y kuşağı gençlerde kurumsal bakıma daha fazla ihtiyaç duyulacağı söylenebilir. Bundan dolayı ilgili bakanlıklar ve yerel yönetimler huzurevi benzeri kurumların sayı ve niteliğini arttırmaya yönelik çalışmalar yapmalıdır. Bu kurumlarda hizmet verecek nitelikli bakım elemanlarının yetiştirilmesine öncelik vermelidir. Ayrıca bu çalışmanın gençlerin huzurevinde kalmayı isteme eğilimlerine bakılacak benzer çalışmalara temel teşkil edeceğini belirtmek gerekmektedir. 


\title{
EXTENDED ABSTRACT
}

\section{The Tendency of the Youth to Prefer to Stay in a Nursing Home: The Case of Nevşehir}

\author{
* \\ Hamza Kurtkapan \\ Nevşehir Hacı Bektaş Veli University
}

In this study, the tendency of generation $Y$ to prefer to stay in a nursing home when they get old is examined; for this purpose, the main reasons for the preference of young people to stay or not to stay in a nursing home and the relationship between these tendencies and life satisfaction are focused. Furthermore, it is aimed to determine the effect of variables such as gender, income and type of high school on life satisfaction in this study. A descriptive cross-sectional study has been conducted with quantitative research design. The study was carried out between February and March 2019 with 775 participants in the 18-27 age group registered in undergraduate education at Nevşehir Hacı Bektaş Veli University.

One of the two major trends of the world in the 21st century is the increase in the proportion of elderly people in the population (WHO, 2007, p.1). Based on the demographic transformation in Turkey, the proportion of individuals aged 65 and older in the total population is increasing rapidly. It is predicted that the population aged 65 years and older which was $8.7 \%$ in 2018 will pass $16 \%$ in 2040, and pass 22\% in 2060 (TÜIK, 2018). It is also estimated that the proportion of children in the 0-14 age group, which was $22.6 \%$ in 2018, will fall below $17 \%$ in 2060 . Population projections demonstrate that by the end of the 2050s, the population above 65 years of age will be more than the population of children aged 0-14 for the first time (TÜIK, 2018).

According to Bayhan, in the conditions of Turkey, today's young people born between 1990 and 2000, constitute the Generation Y (2014, p.4). In demographic terms, a critical period in the second half of the 21th century in Turkey, those in Generation Y will take the first steps in old age. Therefore, the older generation $Y$ of the future deserves more academic interest than those of their predecessors (Kurtkapan, 2019, p.4). There is a need for further work on today's youth who will take steps to old age in a critical historical period. 
Young people belonging to Generation $Y$ who were born in the 90s taking part in the research will step into old age in 2050 and after. In this period, the proportion of elderly in the population in Turkey is predicted to pass the proportion of children covering 0 - 14 age group for the first time and so, the opinions of these young people, who will step into old age, about institutional elderly care in general and whether they prefer to stay in nursing homes in particular, gain importance. The majority of the participants has stated that they do not intend to stay in a nursing home when they got older enough to be in need.

In the study, almost half of the participants who explained the reason for not wanting to stay in a nursing home stated that they did not think of staying in a nursing home care because they wanted to live with their family and / or home. One fifth of the participants stated that they would experience a feeling of ostracisation and loneliness in the nursing home and said that they did not think of staying in a nursing home because she would feel psychologically ill. Another one fifth of the participants say no to staying in a nursing home because they think that the nursing home will not be good and instead, they can get better care in the family. On the other hand, the one sixth stated that they gave no answer because they did not look warmly to the idea of staying in a nursing home and could not be comfortable there.

On the other hand, participants who said that they could stay in nursing homes stated that they could prefer nursing homes in order to avoid placing a strain on anyone (almost half of the participants). Similarly, approximately one fifth of the participants answered that no one in the family would want to look after them. On the other hand, one fourth of the participants stated that they would like to stay in a nursing home because they will be cared for better. Around one sixth of the participants stated that they could choose to stay in a nursing home in order to spend time with their peers.

In this study, it has been determined that participants have moderate life satisfaction. The relationship between the life satisfaction of young people and their tendency to choose a nursing home is also analyzed. As a result of the study, it has been found that the tendency to prefer nursing home is less among the participants with high average life satisfaction score. It is useful to understand the effects of institutional structures on the functioning of social order through the preferences of individuals. Although the nursing home expresses an institutional structure, it is necessary to understand the subjective 
mechanisms that underlie individuals' preferences to stay in nursing homes. In this context, if the preference of staying in a nursing home is a result of life satisfaction, it may be necessary to understand the society in a different way. If those who have a higher level of life satisfaction prefer the nursing home less, this may indicate that the society perceives the preference for living in a nursing home as a kind of deviation from normal. Traditional care at home and in the family requires a balance between individuals' quality of life and their relationship with the environment at the normative level. The negativities that may be encountered within this scope create the need to focus on the differences.

In the study, it has been found that the scores of life satisfaction scale of the youth do not show significant difference according to gender. It has been understood that those who stated that their family's average monthly income is 3250 TL and above have higher life satisfaction than those who stated that it is $1700 \mathrm{TL}$ and below. In addition, it has been determined that the young people who graduated from Imam Hatip (Religious) High School have higher life satisfaction than those who graduated from Regular High School.

It can be said that generation $Y$, the elderly people of the future, needs more institutional care. Therefore, the relevant ministries and local authorities should conduct studies in order to increase the number and quality of nursing home-like institutions. It should give priority to the training of qualified care personnel to serve in these institutions. In addition, it should be noted that this study will be the basis for similar studies to look at the tendency of youth to prefer to stay in a nursing home.

\section{Kaynakça / References}

Aközer, M., Görgün-Baran, A., Kalaycıŏglu, S. Özler, G. Nuhrat, C.R., Ortaç A. ,... , Maran, T. (2011). Türkiye'de yaşlllı dönemine ilişkin beklentiler. Ankara: Aile ve Sosyal Politikalar Bakanlığı Aile ve Toplum Hizmetleri Genel Müdürlüğü Yayınları.

Alperen M. (2013). Sosyo-ekonomi statü açısından yaşlıların aile ilişkileri: Ankara Keçiören örneği. Yayımlanmamış yüksek lisans tezi, Selçuk Üniversitesi, Konya, Türkiye. 
Avşaroğlu, S., Deniz, M. E., ve Kahraman, A. (2005). Teknik öğretmenlerde yaşam doyumu iş doyumu ve mesleki tükenmişlik düzeylerinin incelenmesi. Selçuk Üniversitesi Sosyal Bilimler Enstitüsü Dergisi, 14, 115129.

Balcı, Ş. ve Koçak, M. C. (2017). Sosyal medya kullanımı ile yaşam doyumu arasındaki ilişki: üniversite öğrencileri üzerinde bir araştırma. Öztürk, G. ve Eken, İ. (Eds.). 1. Uluslararası İletişimde Yeni Yönelimler Konferansı içinde (s.34-46), Ankara: Nobel Yayıncllık

Bayhan, V. (2014). Milenyum veya (Y) kuşağı gençliğinin sosyolojik bağlamı. Gençlik Araştırmaları Dergisi, 2(2), 3, 8-25.

Bilge, U., Elçioğlu, Ö., Ünalacak, M. ve Ünlüoğlu, İ. (2014). Türkiye'de yaşlı evde bakım hizmetleri. Euras J FamMed, 3(1), 1-8.

Cirhinlioğlu, F. G. ve Ok, Ü. (2010). İnanç ya da dünya görüşü biçimleri ile intihara yönelik tutum, depresyon ve yaşam doyumu arasındaki ilişkiler. CumhuriyetÜniversitesi Sosyal Bilimler Dergisi, 34, 1-18.

Dağll, A. ve Baysal, N. (2016). Yaşam doyumu ölçeğinin Türkçeye uyarlanması: Geçerlik ve güvenirlik çalışması. Elektronik Sosyal Bilimler Dergisi, 15(59), 1250-1262.

Diener, E. (1984). Subjectivewell-being. Psychological Bulletin 95(3), 542-575.

Diener, E. D., Emmons, R. A., Larsen, R. J. ve Griffin, S. (1985). The satisfactionwith life scale. Journal of PersonalityAssessment, 49(1), 71-75.

Ergin, A., Hatipoğlu, C., Bozkurt, A. İ., Bostancı, M., Atak, B. M., Kısaoğlu, S., ... , Karasu, E. (2011). Tip fakültesi öğrencilerinin yaşam doyumu ve öz-bakım gücü düzeyleri ve etkileyen faktörler. Pamukkale Tıp Dergisi, 3, 144-151.

Görgün Baran, A., Kalınkara, V., Aral, N., Akın, G., Baran G. ve Özkan, Y. (2005). Yaşlı ve aile ilişkileri: Ankara örneğgi. Ankara: Aile ve Sosyal Araştırmalar Genel Müdürlüğ̈ Yayınları, Yayın No: 127.

Kalınkara, V. (2000). Yaşlılıkta sosyal katılım ve kent hizmetleri. Erkan, G. ve Işıkhan, V. (Eds.) Antropoloji ve Yaşlılık, içinde (s. 77-86). Ankara: Hacettepe Üniversitesi Sosyal Hizmetler Yüksekokulu Yayınları.

Kalaycığlu, S. ve Rittersberger -Tılıç, H. (2001). Yaşlı ve genç kuşaklararasında sosyal, kültürel, ekonomik bağların ailenin refah düzeyine etkisi. Yaşlı Sorunları Araştırma Dergisi, 1(2), 65-75.

Kökalan-Çımrın, F. (2009). Küreselleşme, neo liberalizm ve refah devleti ilişkisi üzerine. Muğla Üniversitesi Sosyal Bilimler Enstitüsü Dergisi, 23, 195-203. 
Kurtkapan, H. (2018). Kentte yaşlilık ve yerel yönetim uygulamaları. Ankara: Nobel Yayıncilik.

Kurtkapan, H. (2019). Ünal Şentürk, yaşlılık sosyolojisi, yaşlılığın toplumsal yörüngeleri. İnsan ve Toplum Dergisi, Doi: 10.12658/D0223

Mroczek, K. D. ve Kolarz, M. C. (1998). The effect of age on positive and negative affect: A developmental perspective on happiness, Journal of Personality and Social Psychology, 75(5), 1333-1349.

Özbay, F. (2014). Akrabalık ve komşuluk ilişkileri. Turgut, M. ve Feyzioğlu S. (Eds.), Türkiye Aile Yapısı Araştırması Tespitler ve Öneriler içinde (s. 5690). Ankara: Aile ve Sosyal Politikalar bakanlığı, Aile ve Toplum Hizmetleri Genel Müdürlüğü Yayınları.

Özmete, E. ve Hussein. S. (2017). Türkiye'de yaşl bakım hizmetleri raporu: Avrupa'dan en iyi uygulama örneklerïve Türkiye için bir model tasarımı. Ankara: T.C. Aile ve Sosyal Politikalar Bakanlığı, T.C. Çalışma ve Sosyal Güvenlik Bakanlığı Yayınları.

Riley. M. W. (1976). Social gerontology and the age stratification of society. Atchley, R. C. ve Seltzer, M. M .(Eds.,) in The sociology of aging: Selected readings, Belmont, Calif: Wadsworth

Telef, B. B., Uzman, E. ve Ergün, E. (2013), Öğretmen adaylarında psikolojik iyi oluş ve değerler arasındaki ilişkinin incelenmesi. Turkish Studies, International Periodical For the Languages, Literature and History of Turkish, 8(12), 1297-1307.

Toker B. ve Kalıpçı, M. B. (2019). Demografik değişkenlerin yaşam doyumuna etkisinin lojistik regresyon analizi ile belirlenmesi: Konaklama sektörü örneği. OPUS-Uluslararası Toplum Araştırmaları Dergisi, $12(18$. UIK Özel Say1s1), 544-562. DOI: 10.26466/opus.589382.

Tufan, İ. (2003). Modernleşen Türkiye'de yaşlllık ve yaşlanmak (yaşlanmanın sosyolojisi). İstanbul: Anahtar Kitaplar Yay.

Tufan, İ. ve Yazıcı, S. (2009). Yaşlılıkta kuşaklar arası ilişkiler. Toplum ve Sosyal Hizmet Dergisi, 20(1), 47-52.

Türkiye İstatistik Kurumu. (2018). Haber bülteni: nüfus projeksiyonları 20182080. http//www.tuik.gov.tr/PreHaberBultenleri.do?id=30567 adresinden erişilmiştir.

Türkiye İstatistik Kurumu. (2016). Yaşam Memnuniyeti Araştırması 2015. www.tuik.gov.tr/PdfGetir.do?id=21518 adresinden edinilmiştir. 
World Health Organization. (2007). Global age-friendlycities: a guide. http://www.who.int/ageing/publications/age friendly cities guide/en/ adresinden erişilmiştir.

Yıldız, M. (2018). Lise öğrencilerinde yaşlı ve huzurevi algısı. Yayımlanmamış yüksek lisans tezi, İstanbul Sabahattin Zaim Üniversitesi, İstanbul, Türkiye.

\section{Kaynakça Bilgisi / Citation Information}

Kurtkapan, H. (2020). Y kuşağı gençlerin huzurevinde kalmayı tercih etme eğilimleri: Nevşehir örneği. OPUS-Uluslararası Toplum Araştırmalarn Dergisi, 15(21), 535-554. DOI: 10.26466/opus.622196 